$11-3-2014$

\title{
Discordant Documentation of Obesity Body Mass Index and Obesity Diagnosis in Electronic Medical Records
}

\author{
Jennifer T. Fink \\ George L. Morris III \\ Maharaj Singh \\ David A. Nelson \\ Renee E. Walker \\ Ron A. Cisler
}

Follow this and additional works at: https://aah.org/jpcrr

Part of the Cardiovascular Diseases Commons, Community Health and Preventive Medicine Commons, Dietetics and Clinical Nutrition Commons, and the Health Information Technology Commons

\section{Recommended Citation}

Fink JT, Morris GL, Singh M, Nelson DA, Walker RE, Cisler RA. Discordant documentation of obesity body mass index and obesity diagnosis in electronic medical records. J Patient Cent Res Rev. 2014;1:164-170. doi: 10.17294/2330-0698.1037

Published quarterly by Midwest-based health system Advocate Aurora Health and indexed in PubMed Central, the Journal of Patient-Centered Research and Reviews (JPCRR) is an open access, peer-reviewed medical journal focused on disseminating scholarly works devoted to improving patient-centered care practices, health outcomes, and the patient experience. 


\section{Discordant Documentation of Obesity Body Mass Index and Obesity Diagnosis in Electronic Medical Records}

Jennifer T. Fink, PhD, ${ }^{1,2,3}$ George L. Morris III, MD, ${ }^{1,2,4}$ Maharaj Singh, PhD, ${ }^{1}$ David A. Nelson, PhD, ${ }^{5}$

Renee E. Walker, DrPH, ${ }^{2,4}$ Ron A. Cisler, $\mathrm{PhD}^{1,2,3,4,6}$

${ }^{1}$ Aurora Health Care, Milwaukee, WI

${ }^{2}$ Center for Urban Population Health, Milwaukee, WI

${ }^{3}$ Department of Health Informatics \& Administration, University of Wisconsin-Milwaukee, Milwaukee, WI

${ }^{4}$ Zilber School of Public Health, University of Wisconsin-Milwaukee, Milwaukee, WI

${ }^{5}$ Department of Family and Community Medicine, Medical College of Wisconsin, Milwaukee, WI

${ }^{6}$ Department of Population Health Sciences, University of Wisconsin School of Medicine and Public Health, Madison, WI

\section{Abstract}

Purpose: This study examined concordance between presence of obesity body mass index (BMI), defined as BMI $\geq 30$, in the patient's electronic medical record (EMR) and a documented diagnosis of obesity.

Methods: We conducted a retrospective review of the EMR in a large health care system for a 1-year period (2012). A total of 397,313 patients met the study criteria of having at least one physician visit, being at least 18 years of age, and not being pregnant. Of those, 158,327 (40\%) had a recorded $\mathrm{BMI} \geq 30$. We examined the EMR of these obese patients to determine whether a diagnosis of obesity was recorded, and whether demographics or comorbid diagnoses impacted the likelihood of a recorded obesity diagnosis.

Results: Obesity appeared on the EMR problem list for only $35 \%$ of patients with $\mathrm{BMI} \geq 30$. Obesity diagnosis was documented more frequently in women, middle-aged patients and blacks. The presence of some comorbidities (e.g. sleep apnea, hypertension, diabetes) led to significantly more frequent diagnosis of obesity. There was a significant positive association between the number of comorbid diagnoses per patient and an obesity diagnosis appearing on the problem list.

Conclusions: Obesity remains underrecorded in the EMR problem list despite the presence of obesity BMI in the EMR. Patient demographics and comorbidities should be considered when identifying best practices for weight management. New practices should be patient-centered and consider cultural context as well as the social and physical resources available to patients - all crucial for enacting systems change in a true accountable care environment. (J Patient-Centered Res Rev. 2014;1:164-170.)

Correspondence: Jennifer T. Fink, PhD, 2400 E. Hartford Avenue, NW Quadrant Building B, Room \#6455, Milwaukee, WI, 53201, Phone: 262-323-9393, Email: jennifer.fink@aurora.org

\section{Keywords}

obesity, body mass index, electronic medical record, comorbidities, weight management

\section{Introduction}

Obesity, and its corresponding economic impacts, remains a public health crisis in the United States, with $64 \%$ of adults (approximately 145 million) either overweight or obese. ${ }^{1}$ National survey data indicate that occurrence has gradually increased over the past three decades, although disparities exist between population groups. ${ }^{2}$ Current evidence suggests the prevalence is likely to remain on the rise. ${ }^{3}$ Using a simulation model to predict the economic and public health impact of obesity, Wang and colleagues estimated there will be 65 million more American adults with obesity by 2030 . This increase will be associated with decreased quality of life and disability-free life years, increased diagnoses of fatal and nonfatal diseases, and greater use of health services. It is anticipated that the economic burden of treating obesity and related chronic diseases will increase by $\$ 48-66$ billion per year in the United States. ${ }^{4}$ Because the goals for Healthy People 2010 of reducing obesity prevalence in adults to $15 \%$ and in children to $5 \%$ were not met, ${ }^{5}$ younger American generations may indeed have a shorter life expectancy than their parents if this obesity epidemic is not controlled. ${ }^{6}$

The U.S. Preventive Services Task Force developed recommendations on a broad range of preventive health care services for primary care physicians and, in 2003, recommended that physicians "screen all adult patients for obesity and offer intensive counseling and behavioral interventions to promote sustained weight loss for obese adults."7 These recommendations were based on evidence that intensive counseling can promote modest sustained weight loss and improved clinical outcomes. For example, 
a modest reduction in weight by $5-10 \%$ of initial body weight has been shown to improve cardiovascular disease and reduce diabetes complications often associated with obesity. ${ }^{8}$

Guidelines from health experts such as the World Health Organization, National Institutes of Health, and the U.S. Preventive Services Task Force support the classification and assessment of obesity as an essential component of patients' medical care. ${ }^{7,9,10}$ The classification of obesity begins with a determination of body mass index (BMI), calculated as weight in kilograms divided by height in meters squared, with $\mathrm{BMI} \geq 30$ defined as obese and BMI 25-29.99 as overweight. Because obesity is associated with almost a $30 \%$ increase in overall mortality, ${ }^{11}$ it is extremely important for physicians to identify and manage this condition. Physicians have a significant role in diagnosing and counseling patients with obesity, as their recommendations are an integral initial step in the process to address weight loss through increased physical activity and attention to nutrition. ${ }^{12,13}$ Several studies $^{14-16}$ have demonstrated that physicians often fail to identify, diagnose and manage obesity. In turn, physicians often fail to recommend or refer obese patients to evidencebased treatment.

Numerous reasons and issues relate to a lack of referral for treatment for weight management by physicians, but three common ones are a lack of authoritative information, ${ }^{17}$ frustration by physicians from what they perceive as a lack of motivation on the part of their patients, ${ }^{18}$ and that the best way to go about addressing obesity is not yet known. ${ }^{16}$ National survey results indicate that approximately 58\% of patients with obesity do not receive any counseling to address obesity. ${ }^{19}$ Despite limitations on long-term solutions to address this issue, more can be done in the short term.

Prior to recommending treatment options, a first step to address the issue of obesity is to identify the condition and ensure that it is documented and then placed on the problem list within the health record of the patient. Research has found that with greater regular use of electronic medical records (EMR), obesity is more likely to be recorded in the medical record. ${ }^{20}$ In turn, when a diagnosis of obesity appeared on the problem list, physicians were more likely to address the issue with patients. ${ }^{16,21}$ However, the literature is incomplete because study sample sizes often were small and completed within smaller settings, like a residency program. ${ }^{21,22}$ Limited information exists to explore this issue on a larger systemwide scale.
The purpose of this project was to examine the concordance between obesity BMI $(\mathrm{BMI} \geq 30)$ in the patient's EMR and a diagnosis of obesity in the EMR (i.e. presence of obesity on the EMR problem list - 2012 ICD-9-CM diagnosis code 278.00 for "Obesity, unspecified" and 2012 ICD-9-CM diagnosis code 278.01 for "Morbid obesity"). Based on a review of the literature, we suspected that our health system may have the same issues in not diagnosing obesity when BMI is $\geq 30 .{ }^{14-16}$ For example, Banerjee and colleagues found that $36 \%$ of obese patients had obesity noted on their problem list, ${ }^{16}$ and Waring and colleagues found that obesity was documented in $39 \%$ of mildly obese patient charts, although it was noted in $77 \%$ of moderately/severely obese patient charts. ${ }^{15}$ This discordance is a significant problem when it comes to addressing the chronic condition of obesity. Bardia and colleagues found that most obese patients do not have a diagnosis of obesity or an obesity management plan. ${ }^{23}$ We retrospectively accessed records of patients seen at our institution in 2012 who had a BMI documented in the EMR and a physician visit within 2012. In addition to examining the concordance between $\mathrm{BMI} \geq 30$ and obesity diagnosis, we assessed the various demographic and concurrent comorbid diagnoses that might influence a recorded diagnosis of obesity for patients with $\mathrm{BMI} \geq 30$.

\section{Methods}

\section{Data Sources and Patient Characteristics}

This study is a retrospective review of our institution's EMR from January 1, 2012, to December 31, 2012, and was approved by the local institutional review board. Aurora Health Care is a large health care organization headquartered in Milwaukee, Wisconsin; its fully integrated EMR includes more than 4 million patient records from 15 hospitals and 155 clinics located throughout eastern Wisconsin.

We reviewed all patients who had a documented BMI in their EMR as well as at least one physician visit in 2012. We used data from the patient's first visit in 2012 only in order to avoid duplication of patients. We included patients who were 18 years of age or older as of January 1, 2012. We excluded all women who were pregnant at any time within this time frame by excluding those with ICD-9 code of V22.2. In total, 397,313 patients within Aurora's EMR met the study criteria. Of those, $158,327(40 \%)$ had a BMI $\geq 30$.

We selected comorbid diagnoses of diabetes, hypertension, sleep apnea, hyperlipidemia, coronary artery disease and osteoarthritis to determine if patients with these chronic health conditions increased the likelihood of obesity recorded on the problem list. We chose these chronic health conditions based on their documented association with obesity. ${ }^{7}$ 
Table 1. Distribution of patient demographics across five categories of body mass index

\begin{tabular}{|c|c|c|c|c|c|}
\hline \multirow[b]{2}{*}{ Characteristic } & \multicolumn{5}{|c|}{ Body mass index } \\
\hline & Underweight & Acceptable & Overweight & Obese & Morbidly obese \\
\hline \multicolumn{6}{|l|}{ Gender } \\
\hline Female $(229,668,58 \%)$ & $6,623(3 \%)$ & $69,080(30 \%)$ & $63,331(28 \%)$ & $68,159(30 \%)$ & $22,475(10 \%)$ \\
\hline Male $(167,340,42 \%)$ & $3,994(2 \%)$ & $33,055(20 \%)$ & $62,713(37 \%)$ & $57,205(34 \%)$ & $10,373(6 \%)$ \\
\hline \multicolumn{6}{|l|}{ Age } \\
\hline$\leq 40$ years $(108,033,27 \%)$ & $4,496(4 \%)$ & $37,843(35 \%)$ & $30,624(28 \%)$ & $26,809(25 \%)$ & $8,261(8 \%)$ \\
\hline $41-64$ years $(176,808,45 \%)$ & $2,787(2 \%)$ & $36,898(21 \%)$ & $56,031(32 \%)$ & $63,118(36 \%)$ & $17,974(10 \%)$ \\
\hline$\geq 65$ years $(112,472,28 \%)$ & $3,347(3 \%)$ & $27,478(24 \%)$ & $39,482(35 \%)$ & $35,524(32 \%)$ & $6,641(6 \%)$ \\
\hline \multicolumn{6}{|l|}{ Race } \\
\hline Black $(43,551,12 \%)$ & $1,131(3 \%)$ & $7,485(17 \%)$ & $11,764(27 \%)$ & $16,767(39 \%)$ & $6,404(15 \%)$ \\
\hline White $(320,440,87 \%)$ & $8,448(3 \%)$ & $85,026(27 \%)$ & $103,164(32 \%)$ & $99,213(31 \%)$ & $24,589(8 \%)$ \\
\hline Other $(6,223,2 \%)$ & $281(5 \%)$ & $2,327(37 \%)$ & $2,087(34 \%)$ & $1,291(21 \%)$ & $237(4 \%)$ \\
\hline \multicolumn{6}{|l|}{ Ethnicity } \\
\hline Non-Hispanic $(362,412,95 \%)$ & $9,786(3 \%)$ & $94,052(26 \%)$ & $114,540(32 \%)$ & $113,951(31 \%)$ & $30,083(8 \%)$ \\
\hline Hispanic $(19,570,5 \%)$ & $398(2 \%)$ & $4,080(20 \%)$ & $6,082(34 \%)$ & $7,238(36 \%)$ & $1,772(9 \%)$ \\
\hline
\end{tabular}

Note: Subpopulations for gender, race and ethnicity characteristics do not total the overall study population $(N=397,313)$ due to missing data in the electronic medical records.

Table 1 provides the general demographic breakdown of all 397,313 patients with a recorded BMI as well as subcategories of patients representing underweight (BMI $<19$ for women; BMI < 20 for men), acceptable (BMI $=19$ to 24.99 for women; $\mathrm{BMI}=20$ to 24.99 for men), overweight $(\mathrm{BMI}=25$ to 29.99$)$, obese $(\mathrm{BMI}=30$ to 39.99$)$ and morbidly obese (BMI $\geq 40$ ). Demographic information included gender, age, race and ethnicity. Proportionately, men $(78 \%)$ had greater issues with being overweight, obese or morbidly obese than women $(67 \%)$. Younger patients were proportionately less likely to be overweight or obese/ morbidly obese (61\%) than both elderly patients $(73 \%)$ and middle-aged patients (77\%), although all age group categories were unacceptably high in BMI weight. Black patients had the highest proportion of overweight or obese/ morbidly obese (80\%), followed by whites $(70 \%)$ and patients in other racial categories (58\%). Finally, Hispanic patients, proportionately, had greater issues with being overweight or obese/morbidly obese $(78 \%)$ than nonHispanic patients $(71 \%)$.

\section{Statistical Analyses}

We examined the concordance of EMR obesity BMI (i.e. BMI $<30$ vs. obese BMI $\geq 30$ ) and obesity diagnosis on the EMR problem list (i.e. no ICD-9 code 278.00 and 278.01 vs. ICD-9 code 278.00 or 278.01). A nonparametric chi-squared test was used to determine if the distribution of the proportions of patients with BMI $<30$ or $\geq 30$ was similar for patients with or without obesity diagnosis on the problem list.
For patients with $\mathrm{BMI} \geq 30$, nonparametric chi-squared tests were used to determine if the proportions of patients between categories on demographic variables (i.e. gender, age categories, race and ethnicity) were similar for patients with or without obesity diagnosis on the problem list. Similarly, chi-squared tests were used to determine if the proportions of the patients categorized as having or not having various comorbid diagnoses (i.e. diabetes, hypertension, sleep apnea, hyperlipidemia, coronary arteries disease and osteoarthritis) were similar for patients with or without obesity diagnosis on the problem list. Logistic regression analyses were used to predict the absence ( 0 ) or presence (1) of obesity diagnosis on the problem list by demographic and comorbid variables. For all statistical tests an alpha level of 0.05 was used as level of significance. All statistical analyses were completed using SAS Version 9.2 (SAS Institute Inc., Cary, NC).

\section{Results}

As shown in Table 2 , about $40 \%$ of the patient population with a BMI recorded in the EMR for the year $2012(\mathrm{~N}=397,313)$ had $\mathrm{BMI} \geq 30(\mathrm{n}=158,327)$. The overall concordance or agreement of EMR obesity BMI (i.e. BMI $<30$ vs. obese $\mathrm{BMI} \geq 30$ ) and obesity diagnosis on the EMR problem list (i.e. no ICD-9 code 278.00 and 278.01 vs. ICD-9 code 278.00 or 278.01 ) was $72 \%$. However, of the 158,327 patients with an obesity BMI on the EMR (i.e. BMI $\geq 30$ ), only 54,940 (35\%) also had an obesity diagnosis on their EMR problem list. Conversely, of the 238,986 patients without an elevated BMI (i.e. BMI < 30), 231,365 (97\%) did not have obesity diagnosis on their EMR problem list. 
Table 2. Concordance of electronic medical record (EMR) body mass index $(B M I<30 \mathrm{vs.} \mathrm{BMI} \geq 30)$ and obesity diagnosis on EMR problem list (i.e. no obesity listed vs. obesity listed on EMR problem list) for patients seen at Aurora Health Care in 2012

\begin{tabular}{lccccc}
\hline & \multicolumn{2}{c}{ Obesity on EMR problem list } & & \\
\cline { 2 - 3 } EMR BMI & $\begin{array}{c}\text { No } \\
(\mathbf{3 3 4}, \mathbf{7 5 2}, \mathbf{8 4} \%)\end{array}$ & $\begin{array}{c}\text { Yes } \\
\mathbf{( 6 2 , 5 6 1 , 1 6 \% )}\end{array}$ & & $\begin{array}{c}\text { Obesity BMI \& obesity } \\
\text { problem list agreement* }\end{array}$ & $\boldsymbol{X}^{\mathbf{2}}$ \\
\hline$<30(238,986,60 \%)$ & $231,365(58 \%)$ & $7,621(2 \%)$ & & $231,365(97 \%)$ & $71280.38^{*}$ \\
$\geq 30(158,327,40 \%)$ & $103,387(26 \%)$ & $54,940(14 \%)$ & $54,940(35 \%)$ & \\
\hline
\end{tabular}

${ }^{*} P<0.0001$

**Obesity BMI \& obesity problem list agreement is the number of patients in which either: 1) obesity is not on EMR problem list given that the $E M R B M I$ is < 30; or 2) obesity is on EMR problem list given that the EMR BMI is $\geq 30$.

Table 3 provides a breakdown of the occurrence of obesity diagnosis on the problem list by categories of various demographic characteristics (i.e. gender, age, race and ethnicity) for patients with BMI $\geq 30$ on their EMR. There was statistically significant differential concordance of BMI $\geq 30$ and obesity diagnosis based on gender ( $37 \%$ for females vs. $31 \%$ for males), age ( $35 \%$ for $\geq 65$ years and $36 \%$ for $41-64$ years vs. $30 \%$ for $\leq 40$ years) and race ( $42 \%$ for blacks vs. 34\% for whites and 30\% for other). No significant differences were found by ethnicity (i.e. non-Hispanic vs. Hispanic groups).

Table 4 provides a breakdown of the occurrence of obesity diagnosis on the problem list by other chronic health condition diagnoses (i.e. diabetes, hypertension, sleep apnea, hyperlipidemia, coronary artery disease and osteoarthritis) for patients with BMI $\geq 30$ on their EMR. There was statistically significant differential concordance of $\mathrm{BMI} \geq 30$ and obesity diagnosis based on all relevant comorbid diagnoses, with greater likelihood of obesity being on the problem list if there was a co-occurring diagnosis. More specifically, in order of highest to lowest chi-squared value, obesity diagnosis was more likely to be on the problem list if patients also had a diagnosis of sleep apnea $(30 \% \mathrm{vs}$. $62 \%$ ), hypertension ( $25 \%$ vs. $43 \%$ ), diabetes (30\% vs. $49 \%$ ), hyperlipidemia ( $26 \%$ vs. $42 \%$ ), osteoarthritis (31\% vs. $48 \%$ ) and coronary artery disease (33\% vs. $45 \%)$.

In a separate analysis, we found a statistically significant association $\left(\chi^{2}=12741.20, P<0.0001\right)$ between the number of comorbid diagnoses $(0,1,2-5,6)$ and whether or not obesity was also on the problem list for the 158,327 patients with a $\mathrm{BMI} \geq 30$. As expected, the greater the number of comorbid diagnoses, the more likely obesity was on the problem list. More specifically, obesity was least likely to be on the problem list if patients had zero comorbid diagnoses (18\%), more likely if they had one comorbid diagnosis (30\%), and even more likely if they had two to five comorbid diagnoses $(45 \%)$ or all six comorbid conditions $(77 \%)$.

Logistic regression analyses revealed a number of demographic and comorbidities predictive of obesity diagnosis on the EMR problem list for patients with a $\mathrm{BMI} \geq 30$. These relationships are provided in terms of odds ratios (OR) and revealed that, relative to demographics, being female $(\mathrm{OR}=1.55$ vs. males) or black $(\mathrm{OR}=1.32$ vs. whites) increased the odds of patients having obesity diagnosis on their problem list. In terms of patients having comorbid diagnoses versus not having diagnoses, sleep apnea $(\mathrm{OR}=3.18)$, hypertension $(\mathrm{OR}=1.69)$, diabetes $(\mathrm{OR}=1.63)$, osteoarthritis $(\mathrm{OR}=1.75)$ and hyperlipidemia $(\mathrm{OR}=1.53)$ increased the odds of patients having obesity diagnosis on their problem list. Diagnosis of coronary artery disease $(\mathrm{OR}=1.16)$ marginally increased the odds of patients having obesity diagnosis on their problem list.

Figure 1 displays a receiver-operator characteristic curve showing the strength of predicting obesity diagnosis on the problem list for patients with a $\mathrm{BMI} \geq 30$ with demographic and comorbid diagnoses. The curve, with c-statistic of 0.7016, shows that demographic and comorbid variables, when taken together, can be used to discriminate between patients having obesity diagnosed versus not having obesity diagnosed on the problem list. As a point of reference, a c-statistic of 0.5000 indicates a 50-50 chance that the predictor variables would classify patients as having or not having obesity on the problem list, essentially meaning the variables have no predictive value.

\section{Discussion}

Our examination of the presence of obesity on a patient's problem list when BMI was $\geq 30$ revealed several interesting findings. First and foremost, the relative presence of obesity in a problem list is infrequent, a finding also seen in other 
Table 3. Occurrence of obesity on the electronic medical record (EMR) problem list by categories of various demographic characteristics for patients with EMR body mass index $\geq 30$

\begin{tabular}{|c|c|c|c|}
\hline Characteristic & n (\%) & $\begin{array}{l}\text { Obesity on } \\
\text { EMR problem } \\
\text { list, } \mathbf{n}(\%)\end{array}$ & $x^{2}$ \\
\hline \multicolumn{4}{|l|}{ Gender } \\
\hline Female & $90,634(57 \%)$ & $33,641(37 \%)$ & $537.86^{*}$ \\
\hline Male & $67,578(43 \%)$ & $21,291(31 \%)$ & \\
\hline \multicolumn{4}{|l|}{ Age } \\
\hline$\leq 40$ years & $35,070(22 \%)$ & $10,597(30 \%)$ & $408.25^{*}$ \\
\hline $41-64$ years & $81,092(51 \%)$ & $29,406(36 \%)$ & \\
\hline$\geq 65$ years & 42,165 (27\%) & $14,937(35 \%)$ & \\
\hline \multicolumn{4}{|l|}{ Race } \\
\hline Black & $23,171(16 \%)$ & $9,805(42 \%)$ & $622.22^{*}$ \\
\hline White & $123,802(83 \%)$ & $41,997(34 \%)$ & \\
\hline Other & $1,528(1 \%)$ & $456(30 \%)$ & \\
\hline \multicolumn{4}{|l|}{ Ethnicity } \\
\hline Non-Hispanic & $144,034(94 \%)$ & $50,427(35 \%)$ & 2.83 \\
\hline Hispanic & $9,010(6 \%)$ & $3,076(34 \%)$ & \\
\hline
\end{tabular}

${ }^{*} P<0.0001$.

Note: Subpopulations for gender, race and ethnicity characteristics do not total the overall number of patients with EMR body mass index $\geq 30$ $(N=158,327)$ due to missing data in the electronic medical records.

Table 4. Occurrence of obesity on the electronic medical record (EMR) problem list by other chronic health condition diagnoses for patients with EMR body mass index $\geq 30$

\begin{tabular}{|c|c|c|c|}
\hline Characteristic & n (\%) & $\begin{array}{l}\text { Obesity on } \\
\text { EMR problem } \\
\text { list, n (\%) }\end{array}$ & $x^{2}$ \\
\hline \multicolumn{4}{|l|}{ Sleep apnea } \\
\hline No & $134,882(85 \%)$ & $40,491(30 \%)$ & $8807.39 *$ \\
\hline Yes & $23,445(15 \%)$ & $14,449(62 \%)$ & \\
\hline \multicolumn{4}{|l|}{ Hypertension } \\
\hline No & $69,965(44 \%)$ & $17,303(25 \%)$ & $5498.75^{*}$ \\
\hline Yes & $88,362(56 \%)$ & 37,637 (43\%) & \\
\hline \multicolumn{4}{|l|}{ Diabetes } \\
\hline No & $117,317(74 \%)$ & $34,693(30 \%)$ & $5256.92^{*}$ \\
\hline Yes & $41,010(26 \%)$ & $20,247(49 \%)$ & \\
\hline \multicolumn{4}{|l|}{ Hyperlipidemia } \\
\hline No & $75,186(47 \%)$ & $19,752(26 \%)$ & $4489.88^{*}$ \\
\hline Yes & $83,141(53 \%)$ & $35,188(42 \%)$ & \\
\hline \multicolumn{4}{|l|}{ Osteoarthritis } \\
\hline No & $124,167(78 \%)$ & $38,430(31 \%)$ & $3571.75^{*}$ \\
\hline Yes & $34,160(22 \%)$ & $16,510(48 \%)$ & \\
\hline \multicolumn{4}{|c|}{ Coronary artery disease } \\
\hline No & $137,330(87 \%)$ & $45,405(33 \%)$ & $1225.62^{*}$ \\
\hline Yes & $20,997(13 \%)$ & $9,535(45 \%)$ & \\
\hline
\end{tabular}

${ }^{*} P<0.0001$.
EMR surveys. ${ }^{14-16}$ Obesity diagnosis was documented in a patient problem list only $35 \%$ of the time in this group of 158,327 patients with a $\mathrm{BMI} \geq 30$. Obesity was documented more frequently in women, in middle-aged patients and in black patients. These demographic divisions were reported in prior studies, although whites rather than blacks generally had higher obesity documentation. Other reports highlight the increased success with weight reduction when physicians document and discuss weight loss. ${ }^{24,25}$ Unfortunately, evidence-based weight management strategies have not proved sustainable in clinical practice, and few published primary care-based obesity treatment trials have yielded significant long-term outcomes. ${ }^{26}$ Reports highlight that behaviorally based treatments are safe and effective for weight loss and maintenance but note that the majority of studies had high attrition rates, lacked postdiscontinuation data and often lacked statistical validity. ${ }^{27}$ These results may influence physician willingness to add obesity to the problem list.

The absence of obesity documentation can have a negative impact on future patient health, making this documentation step an important health intervention. Weight is considered a modifiable risk factor, and alterations in BMI are associated with reduced risk. A large meta-analysis of randomized control trials has shown that weight reduction can both prevent and treat hypertension..$^{28}$ Obesity is recognized as a modifiable factor in the development of diabetes, and physical activity and weight control have been shown to be important in diabetes prevention and management. ${ }^{29,30} \mathrm{~A}$ recent study on the effect of obesity on knee osteoarthritis reported a reduction in pain and increase in function and improvement in quality-of-life measures when a regimen of diet plus exercise reducing BMI was compared to either diet or exercise independently. ${ }^{31}$

Some of our findings are difficult to explain. For example, we found that the diagnosis of obesity was documented more often for some types of comorbid conditions, such as sleep apnea, hypertension and diabetes, and less often for others such as coronary artery disease and osteoarthritis. We found that a more acute and possibly more definitive diagnosis such as coronary artery disease was associated with a $50 \%$ or more reduction in obesity documentation. We assert that practitioners might make a more direct connection between obesity and other comorbidities such as sleep apnea, hypertension and diabetes. Alternatively, comorbid conditions such as coronary artery disease and osteoarthritis may represent more advanced comorbidities associated with obesity and that practitioner documentation 


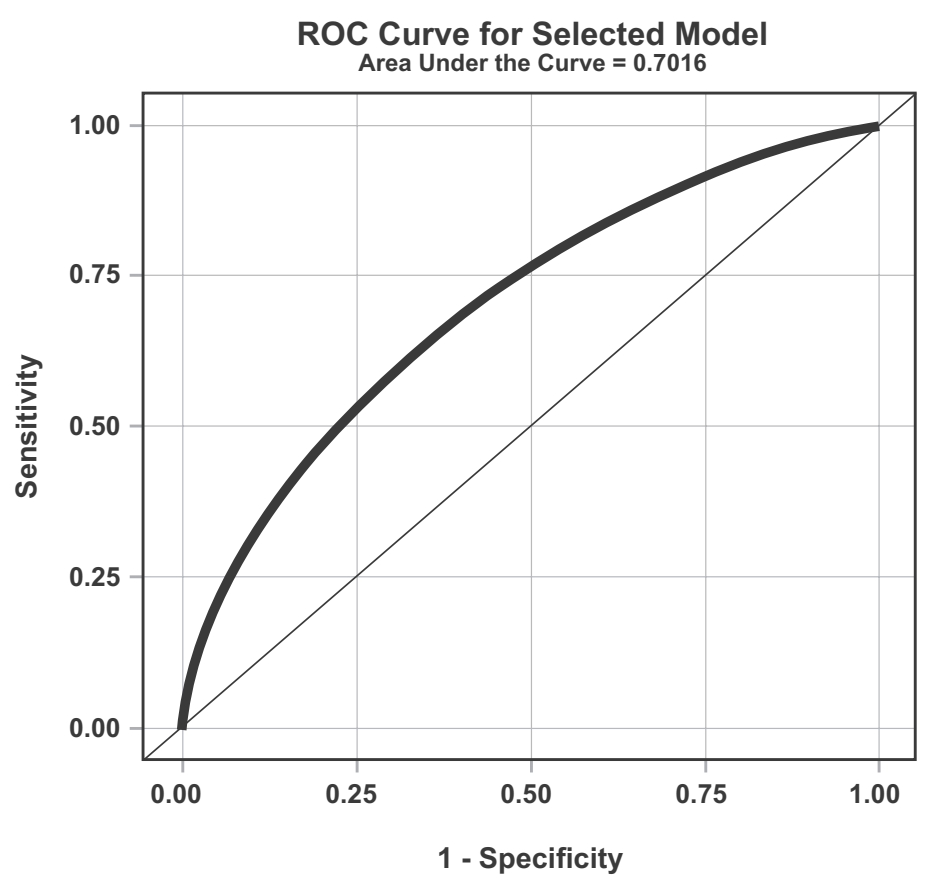

Figure 1. Receiver-operator characteristic (ROC) curve using demographic and comorbid diagnosis variables in predicting obesity diagnosis in the electronic medical record for patients with body mass index $\geq 30$.

of obesity might therefore be perceived as less crucial. Consistent with expectations, we also found a significant positive association between the number of comorbid diagnoses and the documentation of obesity on the problem list; the more diagnoses, the more likely obesity diagnosis was documented on the EMR. Taken together, it may be that health care providers view diagnosing and treating patients for obesity as secondary to treating more severe and advanced chronic health conditions; there could be a perceived futility by caregivers in documenting obesity as a potential root cause of the other comorbidities they are documenting.

Our study does suffer from limitations inherent in reviewing large data sets. The entry of patient information into the EMR, including height and weight, which are required in determining BMI, can be unreliable. Individuals receiving specialty care not pertinent to the diagnosis of obesity may not have their data related to obesity entered. Furthermore, physicians have reported they will often fail to enter obesity into a problem list if it is not relevant to the encounter. Another limitation may be that the EMR does not capture the counseling regarding weight management that the physician delivers despite not entering obesity into the problem list. Results from a survey conducted by our research team of
Wisconsin physicians suggested there are multiple barriers to adding obesity to the problem list, including lack of time, treatment availability and treatment effectiveness as well as patient resistance. $^{32}$

\section{Conclusions}

Obesity often is not recorded in the EMR problem list despite documentation of obesity BMI in the patient EMR. One explanation for this could be that obesity among American adults is common. Two-thirds of adults are either overweight or obese, and this may be overwhelming for primary care physicians to deal with in the context of their medical practice. Patients may see their providers for a number of reasons and, while a discussion about weight may occur, there may be more pressing medical issues that prevent it from being added to the problem list. Closely aligned with this issue is the difficulty physicians and other providers may have in talking with their patients about the issue of obesity. This issue may be exacerbated by differences of gender, race and culture between the provider and the patient. Finally, despite knowing what works in terms of achieving successful weight loss at the individual level, change at the community level is much more difficult to achieve. This is more noticeable within low-income communities where there are fewer resources that support healthy eating and active living and greater disparities of overweight and obesity.

Future research must identify long-term successful strategies for weight reduction that influence health care providers to include the diagnosis of obesity on the EMR problem list. Improving weight reduction outcomes and including them in best practices is integral to transforming obesity and weight management into a systemic health care change in true accountable care organizations. A synergistic approach to solving this transformation must be conducted. Researchers and practitioners must consider why practitioners fail to document obesity and work toward finding new translational and systematic approaches in the management of chronic diseases. Innovative, patient-centered approaches that are developed by patients for patients are required. These approaches should consider cultural context and social and physical resources available to patients. Identifying and assessing early-stage metabolic syndrome, for example, will advance our secondary prevention efforts in chronic disease management.

\section{Conflicts of Interest}

None. 


\section{References}

1. Finkelstein EA, Trogdon JG, Brown DS, Allaire BT, Dellea PS, Kamal-Bahl SJ. The lifetime medical cost burden of overweight and obesity: implications for obesity prevention. Obesity (Silver Spring). 2008;16:1843-8.

2. Wang Y, Beydoun MA. The obesity epidemic in the United States-gender, age, socioeconomic, racial/ethnic, and geographic characteristics: a systematic review and meta-regression analysis. Epidemiol Rev. 2007;29:6-28.

3. Zhang Q, Wang Y. Trends in the association between obesity and socioeconomic status in U.S. adults: 1971 to 2000. Obes Res. 2004; 12:1622-32.

4. Wang YC, McPherson K, March T, Gortmaker SL, Brown M. Health and economic burden of the project obesity trends in the USA and the UK. Lancet. 2011;378:815-25.

5. U.S. Department of Health and Human Services. Healthy People 2010. http://www.healthypeople.gov. Accessed Feb. 1, 2014.

6. Olshansky SJ, Passaro DJ, Hershow RC, et al. A potential decline in life expectancy in the United States in the 21 st century. $N$ Engl J Med. 2005;352:1138-45.

7. U.S. Preventive Services Task Force. Screening for obesity in adults, December 2003. http://www.ahrq.gov/clinic/uspstf/uspsobes. htm\#related. Accessed July 1, 2009.

8. Knowler WC, Barrett-Connor E, Fowler SE, et al. Reduction in the incidence of type 2 diabetes with lifestyle intervention or metformin. N Engl J Med. 2002;346:393-403.

9. Obesity: preventing and managing the global epidemic. Report of a WHO consultation. World Health Organ Tech Rep Ser. 2000; 894:1-253.

10. National Institutes of Health. Clinical Guidelines on the Identification, Evaluation, and Treatment of Overweight and Obesity in Adults-The Evidence Report. Obes Res. 1998;6 Suppl 2:51S-209S.

11. Prospective Studies Collaboration, Whitlock G, Lewington S, et al. Body-mass index and cause-specific mortality in 900000 adults: collaborative analyses of 57 prospective studies. Lancet. 2009;373:1083-96.

12. Kant AK, Miner P. Physician advice about being overweight: association with self-reported weight loss, dietary, and physical activity behaviors of US adolescents in the National Health and Nutrition Examination Survey, 1999-2002. Pediatrics. 2007;119:e142-7.

13. Kreuter MW, Chheda SG, Bull FC. How does physician advice influence patient behavior? Evidence for a priming effect. Arch Fam Med. 2000;9:426-33.

14. Schriefer SP, Landis SE, Turbow DJ, Patch SC. Effect of a computerized body mass index prompt on diagnosis and treatment of adult obesity. Fam Med. 2009;41:502-7.

15. Waring ME, Roberts MB, Parker DR, Eaton CB. Documentation and management of overweight and obesity in primary care. J Am Board Fam Med. 2009;22:544-52.

16. Banerjee ES, Gambler A, Fogleman C. Adding obesity to the problem list increases the rate of providers addressing obesity. Fam Med. 2013;45:629-33.

17. National Heart, Blood, and Lung Institute. Clinical Guidelines on the Identification, Evaluation, and Treatment of Overweight and Obesity in Adults. http://www.nhlbi.nih.gov/guidelines/obesity. Accessed June 16, 2013.
18. Hong Y, Ory MG, Lee C, Wang S, Pulczinksi J, Forjuoh SN. Walking and neighborhood environments for obese and overweight patients: perspectives from family physicians. Fam Med. 2012;44:336-41.

19. Kraschnewski JL, Sciamanna CN, Pollak KI, Stuckey HL, Sherwood NE. The epidemiology of weight counseling for adults in the United States: a case of positive deviance. Int J Obes (Lond). 2013;37:751-3.

20. Bordowitz R, Morland K, Reich D. The use of an electronic medical record to improve documentation and treatment of obesity. Fam Med. 2007;39:274-9.

21. McArtor RE, Iverson DC, Benken D, Dennis LK. Family practice residents' identification and management of obesity. Int J Obes Relat Metab Disord. 1992;16:335-40.

22. Clothier N, Marvel MK, Cruickshank CS. Does presenting patients' BMI increase documentation of obesity? Med Educ Online. 2002; 7:1-4.

23. Bardia A, Holtan SG, Slezak JM, Thompson WG. Diagnosis of obesity by primary care physicians and impact on obesity management. Mayo Clin Proc. 2007;82:927-32.

24. Baer HJ, Karson AS, Soukup JR, Williams DH, Bates DW. Documentation and diagnosis of overweight and obesity in electronic health records of adult primary care patients. JAMA Intern Med. 2013;173:1648-52.

25. Baron RB. Telling patients they are overweight or obese: an insult or an effective intervention?: comment on "The influence of physician acknowledgment of patients' weight status on patient perceptions of overweight and obesity in the United States". Arch Intern Med. 2011;171:321-2.

26. Tsai AG, Wadden TA. Treatment of obesity in primary care practice in the United States: a systematic review. J Gen Intern Med. 2009;24:1073-9.

27. Leblanc ES, O'Connor E, Whitlock EP, Patnode CD, Kapka T. Effectiveness of primary care-relevant treatments for obesity in adults: a systematic evidence review for the U.S. Preventive Services Task Force. Ann Intern Med. 2011;155:434-47.

28. Neter JE, Stam BE, Kok FJ, Grobbee DE, Geleijnse JM. Influence of weight reduction on blood pressure: a meta-analysis of randomized controlled trials. Hypertension. 2003;42:878-84.

29. Sigal RJ, Kenny GP, Wasserman DH, Castaneda-Sceppa C, White RD. Physical activity/exercise and type 2 diabetes: a consensus statement from the American Diabetes Association. Diabetes Care. 2006;29:1433-8.

30. Hu FB, Manson JE, Stampfer MJ, et al. Diet, lifestyle, and the risk of type 2 diabetes mellitus in women. N Engl J Med. 2001;345:790-7.

31. Messier SP, Mihalko SL, Legault C, et al. Effects of intensive diet and exercise on knee joint loads, inflammation, and clinical outcomes among overweight and obese adults with knee osteoarthritis: the IDEA randomized clinical trial. JAMA. 2013;310:1263-73.

32. Morris GL 3rd, Chapman K, Nelson D, Cisler RA, Walker R. Wisconsin physician survey on diagnosis and treatment of obesity. (abstr.) J Patient-Centered Res Rev. 2014;1:147-8.

(C) 2014 Aurora Health Care, Inc. 